\title{
BMJ Open Mechanisms for addressing and managing the influence of corporations on public health policy, research and practice: a scoping review
}

\author{
Melissa Mialon (10 , ${ }^{1,2}$ Stefanie Vandevijvere, ${ }^{3}$ Angela Carriedo-Lutzenkirchen, ${ }^{4}$ \\ Lisa Bero, ${ }^{5}$ Fabio Gomes, ${ }^{6}$ Mark Petticrew, ${ }^{7}$ Martin McKee (10 , David Stuckler, ${ }^{8}$ \\ Gary Sacks ${ }^{9}$
}

To cite: Mialon M, Vandevijvere S, CarriedoLutzenkirchen A, et al. Mechanisms for addressing and managing the influence of corporations on public health policy, research and practice: a scoping review. BMJ Open 2020;10:e034082. doi:10.1136/ bmjopen-2019-034082

- Prepublication history and additional material for this paper are available online. To view these files, please visit the journal online (http://dx.doi. org/10.1136/bmjopen-2019034082).

Received 05 September 2019 Revised 05 March 2020 Accepted 18 May 2020
Check for updates

(C) Author(s) (or their employer(s)) 2020. Re-use permitted under CC BY-NC. No commercial re-use. See rights and permissions. Published by BMJ.

For numbered affiliations see end of article.

Correspondence to Dr Melissa Mialon; melissa_mialon@hotmail.fr

\section{ABSTRACT}

Objective We identified mechanisms for addressing and/ or managing the influence of corporations on public health policy, research and practice, as well as examples of where these mechanisms have been adopted from across the globe.

Design We conducted a scoping review. We conducted searches in five databases on 4 June 2019. Twentyeight relevant institutions and networks were contacted to identify additional mechanisms and examples. In addition, we identified mechanisms and examples from our collective experience working on the influence of corporations on public health policy, research and practice.

Setting We identified mechanisms at the national, regional and global levels.

Results Thirty-one documents were included in our review. Eight were peer-reviewed scientific articles. Nine discussed mechanisms to address and/or manage the influence of different types of industries; while other documents targeted specific industries. In total, we identified 49 mechanisms for addressing and/or managing the influence of corporations on public health policy, research and practice, and 43 of these were adopted at the national, regional or global level. We identified four main types of mechanisms: transparency; management of interactions with industry and of conflicts of interest; identification, monitoring and education about the practices of corporations and associated risks to public health; prohibition of interactions with industry. Mechanisms for governments $(n=17)$ and academia $(n=13)$ were most frequently identified, with fewer for the media and civil society.

Conclusions We identified several mechanisms that could help address and/or manage the negative influence of corporations on public health policy, research and practice. If adopted and evaluated more widely, many of the mechanisms described in this manuscript could contribute to efforts to prevent and control non-communicable diseases.

Trial registration details The protocol was registered with the Open Science Framework on 27 May 2019 (https://osf.io/xc2vp).

\section{Strengths and limitations of this study}

- This review is the first attempt to develop an inventory of mechanisms for addressing and managing the influence of corporations on public health policy, research and practice.

- Many of the mechanisms identified in our review have been developed with no restriction on the type of industries targeted.

- The list compiled here is non-exhaustive and by nature, subject to changes, as an increasing number of governments and other institutions take measures to prevent undue influence from industry.

- Not all mechanisms have yet been thoroughly evaluated; therefore, we did not assess the validity of the included studies.

- Mechanisms at the subnational level have not been included in our study.

\section{BACKGROUND}

There is growing evidence, coupled with public awareness, that the economic power of corporations, particularly that of large transnationals, has led to the defeat, delay and weakening of public health policies around the world. ${ }^{1-3}$ Perhaps the best evidence of the harmful influence of corporations on public health policy is in the field of tobacco control. In the $1990 \mathrm{~s}$, during litigation in the USA, leading tobacco companies released large quantities of internal documents, ${ }^{45}$ revealing how, over decades, they sought to deny the threat that tobacco posed to health and to thwart measures to reduce smoking. ${ }^{6-8}$ Recent research has shown that influence of tobacco industry has resulted in a policy shift towards industry interests in some regions, such as the European Union. ${ }^{9}$ Tobacco continues to kill millions. ${ }^{10}$ An emerging body of evidence is revealing the use of similar corporate efforts to defeat, delay and weaken the public health 
policies and influence research and practice, from a range of sectors including the alcohol, food, gambling, oil and pharmaceutical industries, among others. ${ }^{11-15}$ These corporate practices that have a negative impact on health, and that are used across industries, are increasingly referred to as 'commercial determinants of health' in the literature. ${ }^{16}$

Industry efforts to influence public policy, research and practice are often referred to as 'corporate political activity' (CPA). The CPA includes: coalition management (influence on third parties such as health organisations, communities and the media); information management (manipulation of the evidence base, through the funding of research, ghost-writing, and so on); direct and indirect involvement in policy-making; litigation or the threat of legal actions; and discursive strategies seeking to frame the dominant narrative in their favour. ${ }^{8}$

Several institutions have been established to monitor the influence of corporations on public health policy, research and practice, such as Corporate Europe Observatory in Europe and US Right to Know in the USA (see online supplementary file 1 for a non-exhaustive list of such organisations). Major reviews of the determinants of health also increasingly and explicitly examine the influence of corporations on public health policy, research and practice. ${ }^{3}$ Approaches have recently been developed to analyse this influence systematically. The 'Corporate Permeation Index' developed by Lima and Galea measures "the extent to which corporations are embedded in the political, legal, social, economic and cultural fabric of a country". ${ }^{17}$ This index seeks to quantify the penetration of corporations in a given country, and was recently implemented for 148 countries over the period $2010-5 .{ }^{17}$ The results showed extensive international variation. ${ }^{17}$ The $\mathrm{WHO}$, as well as institutions in academia and civil society, have made recommendations to identify and monitor the influence of the tobacco industry on public health policy, research and practice. ${ }^{18-20}$ Mialon et al built on this work and developed a step-by-step approach to monitor the CPA of the food industry within countries, using publicly available information. ${ }^{11}$ To date, the approach has been implemented in more than 20 countries. ${ }^{21-27}$ One commonly identified drawback of such approaches is that they are limited by a lack of relevant and comprehensive publicly available information for most industries other than tobacco, where millions of internal documents are now freely available to the public. ${ }^{21} 232427$ Evidence of this influence for other industries is typically sparse and not systematically compiled. It is obtained from a range of sources, including internal documents, primarily leaked by whistle-blowers, publicly available information (eg, from media releases, companies websites, data on lobbying, and so on) and interviews with those who interact with these companies.

National health authorities and civil society organisations have increasingly been concerned with the weakening, delay and obstruction of public health policies due to harmful corporate practices. ${ }^{28} 29$ There is also increasing awareness and acceptance among the public health community, particularly in high-income countries, that interactions with these industries require extreme caution, and, at the minimum, transparency coupled with a detailed understanding of their mode of operation..$^{30} 31$ The public health community looks for inspiration to the WHO Framework Convention on Tobacco Control (FCTC) ${ }^{32}$ with recent calls for a Framework Convention on Food Systems (FCFS) ${ }^{3}$ and a Framework Convention on Alcohol Control (FCAC).$^{33}$ Article 5.3 of the FCTC bars any interactions between governments and the tobacco industry except for implementing tobacco control, led by public health officials. ${ }^{32}$ As of December 2018, 181 countries had ratified the WHO FCTC, covering $90 \%$ of the world population. ${ }^{34}$ The extent of implementation of key FCTC regulatory measures in countries is significantly associated with lower smoking prevalence ${ }^{35}$ However, the tobacco industry, often through pseudo-scientific front groups, still wields influence that allows it to avoid or water down regulatory initiatives. ${ }^{36}$

The demand for mechanisms to protect the policy process from undue corporate influence is growing. One example of how this became evident is when, in 2012, Member States requested the World Health Assembly (Resolution WHA65.6) to develop risk assessment, disclosure and management tools to safeguard against conflicts of interest (COI) in policy development and implementation of nutrition programmes. ${ }^{37}$ The WHO also recently declared that it would no longer partner with alcohol industry actors during the development of policies to reduce harmful drinking. ${ }^{38}$ The need for guidance on how to address and manage undue influence from corporations is also evident in research and practice. ${ }^{39} 40$

Identification and monitoring of the industry influence on public health policy, research and practice is a necessary but insufficient step in protecting and promoting public health. It is essential that international organisations, governments, academia, the media and the civil society are equipped to tackle potential threats to global health. Our study objective was, therefore, to identify mechanisms for addressing and/or managing the influence of corporations on public health policy, research and practice, as well as examples of where these mechanisms have been adopted.

\section{METHODS}

We conducted a scoping review, where we searched scientific publications (peer-reviewed articles, letters to the editor, commentaries, and so on) and reports from governments, international organisations and civil society. We excluded books, as well as presentations from conferences, and other events where no full articles were available.

A scoping review was deemed to be the most suitable method for this study as we intended to summarise evidence from a heterogeneous body of research, from academia, governments, civil society organisations and 
other actors in public health. ${ }^{41}$ A scoping review also advances knowledge in an emerging field of research, which is the case for mechanisms to address the influence of corporations on public health. ${ }^{41}$ In addition, it helps examine the nature of available research and research gaps in the literature, which could inform future research. ${ }^{41}$

We used the Preferred Reporting Items for Systematic Reviews and Meta-Analyses (PRISMA) Extension for Scoping Reviews (PRISMA-ScR, see online supplementary file 2) to prepare our scoping review protocol and our manuscript. The protocol was revised by the research team and registered with the Open Science Framework on 27 May 2019 (https://osf.io/xc2vp).

In our scoping review, the term 'mechanism' refers to: policies, regulations, guidelines, codes of conduct, frameworks, standards, initiatives or other tools to address and/ or manage the influence of corporations on public health policy, research and practice.

The terms 'industry' and 'corporations' are employed interchangeably in this manuscript to refer to the manufacturers, wholesalers, retailers, distributors, food service providers, as well as producers of raw material. We also include those organisations acting on their behalf, overtly or covertly, including some trade associations, public relations firms, 'philanthropic' organisations, research institutions and other individuals and groups.

\section{Database searches}

Search strategy

The development of the search strategy was informed by previous systematic and scoping reviews that analysed the influence of corporations on public health policy, research and practice ${ }^{71213}$ or that presented mechanisms to address and/or manage that influence (for the food industry, for example ${ }^{40}$ ). We used keywords and Medical Subject Headings (MeSH) terms. The search strategy was developed with the help of a librarian at the University of Antioquia, Colombia.

We conducted systematic searches in five databases:

- Web of Science Core Collection (Web of Knowledge interface);

- BIOSIS (Web of Knowledge interface);

- MEDLINE (Web of Knowledge interface);

- Embase (Embase interface);

- Scopus (Scopus interface).

The terms used in the search strategy were tailored to the requirements of each database and included ( (corporat* or industr* or compan* or business* or firm*) AND (address* or manag* or 'guid*' or 'codes of conduct' or framework* or standard* or governance)). In addition, we searched the following key terms in the titles only, as a broader search yielded too many irrelevant results: ( (diet or nutrition or food or obesity or alcohol or drink or pharma* or gambl* or tobacco or smok* or cigarette* or oil or "public health') AND (interact* or conflict* or "public*private" or poli* or legislat* or lobb*)).
Our search strategy for Web of Science Core Collection (Web of Knowledge interface) was:

$\mathrm{TO}=($ (corporat* or industr* or compan* or business* or firm*) AND (address* or manag* or "guid*" or "codes of conduct" or framework* or standard* or governance)) AND TI $=(($ diet or nutrition or food or obesity or alcohol or drink or pharma* or gambl* or tobacco or smok* or cigarette* or oil or "public health") AND (interact* or conflict* or "public*private" or poli* or legislat* or lobb*))

Indexes=SCI-EXPANDED, SSCI, A\&HCI, CPCI-S, CPCI-SSH, BKCI-S, BKCI-SSH, ESCI, CCR-EXPANDED, IC Timespan=2003 to 2019

The search strategies for other databases are presented in online supplementary file 3. Databases were searched on 4 June 2019.

\section{Eligibility criteria}

To be included in this review, publications had to:

- Be published in 2003 and later, when the WHO-FCTC came into effect;

- Be published in English, French, Spanish, Portuguese, or Italian-languages for which members of our team had at least working proficiency;

- Analyse, use, compare, propose or evaluate one or several mechanisms for addressing and/or managing the influence of corporations on public health policy, research and/or practice;

- Focus on the influence of the alcohol, food, gambling, oil, pharmaceutical and/or tobacco industries on public health policy, research and practice;

- Focus on mechanisms at the international, regional (eg, Europe) or national level.

\section{Selection of sources of evidence}

All citations identified were downloaded and imported to the web-based bibliographic manager F1000 Workspace, where duplicate citations were removed. Data extraction and analysis were led by the first author. MM screened all titles and abstracts, when available, for eligibility. GS double-screened $10 \%$ of the material. MM then obtained the full-texts of potential eligible material. When publications were not available online, MM contacted the first authors of the materials to obtain a copy of the documents $(n=13)$. MM assessed the eligibility of that material against the eligibility criteria. GS assessed the eligibility of $10 \%$ of the documents. Disagreement was resolved by consensus after discussion between MM and GS. For documents that were included in our review, MM searched their bibliographic reference sections (backward searches) and searched documents that were citing them; using Scopus (forward searches) to identify additional relevant material.

\section{Additional searches}

Twenty-eight institutions and networks working on the industry influence on public health policy, research and practice, as detailed in online supplementary file 1, were 
contacted in May 2019 to identify additional mechanisms and examples. These institutions were identified through the authors' networks. Only one of these institutions answered our requests. In addition, we identified mechanisms and examples of their adoption from our collective experience working on the influence of corporations on public health policy, research and practice.

We included documents from the grey literature, including from international agencies (eg, WHO, World Bank, and so on), national government agencies, universities, academic journals, international professionals associations, the media, research funders and civil society organisations.

\section{Data charting process and data items}

Data was charted by MM in an Excel table, and the variables for which data were sought were:

- Whether or not the study was funded by corporations or had authors that were employed by corporations in the alcohol, food, gambling, oil, pharmaceutical or tobacco industries (as disclosed in the documents identified through our searches);

- Individuals and institutions targeted by the mechanism: governments and international organisations (with details about specific institutions targeted by the mechanisms within these organisations); academia (including researchers, universities, scientific journals, research funders, ethics review boards, and so on), the media and the civil society;

- Details about the mechanism for addressing and/or managing the influence of corporations on public health policy, research and practice, including the type of mechanism described;

- Information about specific examples where the mechanism has been adopted, either fully or to some extent, including the name of the country, the name of the policy and the URL.

\section{Synthesis of results}

We identified four broad types of mechanisms for addressing and managing the influence of corporations on public health policy, research and practice, through our interpretation of the data, and as presented at the beginning of our results section. Most mechanisms identified in this review pertain to one or more of these four broad categories

We present the results of our review in two tables: one table with mechanisms for governments and international organisations and one table with mechanisms for academia, the media and civil society. We decided to first present data for individuals and institutions in governments as they may have a legal obligation to address undue influence from corporations and conflicts of interest, while this might not be the case for other actors in public health.

We then grouped each mechanism by institution (ministries, universities, academic journals, and so on), in no specific order. Where multiple mechanisms targeting particular aspects of corporate influence were identified, we only included the most stringent mechanisms, as determined by ourselves.

We also include examples where these mechanisms have been adopted, fully or to some extent, as identified in the documents collected during our systematic searches or as identified through additional searches. The URLs for the examples included in our scoping review are available in online supplementary file 4 . We made a particular effort to represent a broad range of countries from different regions of the globe in these examples, although our list is non-exhaustive.

\section{Exclusion criteria}

We excluded documents funded by corporations or whose authors were employed by corporations in the alcohol, food, gambling, oil, pharmaceutical and tobacco industries (as disclosed in the documents identified through our searches), as these represented an inherent COI in the development of mechanisms to address and/or manage the influence of these industries.

In our analysis, we excluded mechanisms:

- that were proposed or developed by the industries mentioned above when these were presented among other mechanisms in non-industry funded documents (eg, reports from multi-stakeholders platforms);

- only addressing marketing practices, for example:

- the sponsorship of sport;

- the interactions between pharmaceutical companies and doctors, pharmacists and other healthcare professionals (including during their training) when those have the sole purpose of selling products.

- targeted at corporations for managing their interactions with government, academia, the media and the civil society;

- targeting corporate practices that are almost universally illegal, such as criminal activity and bribery of government officials, although we recognise that these other forms of influence exist. These are beyond the scope of this manuscript.

We also excluded documents that did not analyse, use, compare, propose or evaluate a mechanism per se, but instead discussed its adoption in a specific context (for example the adoption in nine countries of a transparency policy for the interactions between healthcare professionals and the pharmaceutical industry ${ }^{42}$ ). In this case, we used these examples in our results section to illustrate instances where a mechanism was adopted.

Patient and public involvement statement

Patients and the public were not involved in this research.

\section{RESULTS}

The PRISMA flow diagram for our scoping review is presented in figure 1. In total, 2015 documents were identified in the databases searches (excluding duplicates). 


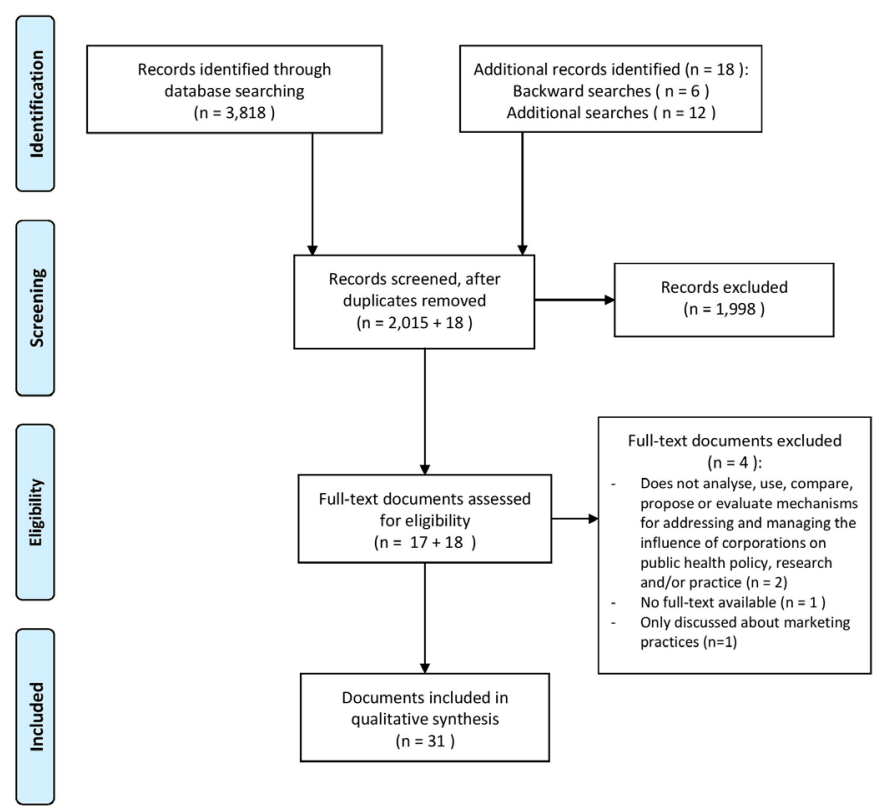

Figure 1 PRISMA (Preferred Reporting Items for Systematic Reviews and Meta-Analyses) flow diagram.

After screening of their titles and abstracts, 1998 documents were excluded and 17 were included. In addition, 6 documents were identified through backward searches and 12 documents were found through additional searches. No new documents were identified through forward searches. In total, 35 full-texts were included for analysis. Subsequently, two articles were excluded because they did not present mechanisms for addressing and/or managing the industry influence; one article was excluded because we could not retrieve its full-text, despite contacting its first author; and one article was excluded because it only discussed marketing practices.

In total, 31 documents were included in our scoping review. All references included in our scoping review came from high-income countries, in particular the USA $(n=9)$. Eight documents were published by international organisations based in France, Switzerland and the USA. Only eight documents were peer-reviewed articles. Other documents included letters to the editors, commentaries and other pieces in scientific/clinical journals, as well as reports by national and international organisations. Nine documents discussed mechanisms to address and/or manage the influence of all sorts of industries. The other documents targeted specific industries (these categories are not mutually exclusive): six for the alcohol industry; seven for the food industry; five for the gambling industry; five for the pharmaceutical industry; and six for the tobacco industry. None of the documents discussed mechanisms to address and/or manage the influence of the oil industry. Most documents included mechanisms for governments $(\mathrm{n}=17)$ and academia (including researchers, universities, scientific journals, research funders, ethics review boards, and so on) $(n=13)$. Three documents proposed mechanisms for civil society and one for the media. We found many examples where these mechanisms have been adopted, as described below.

Many of the mechanisms identified in our review, as discussed in the sections below, focus on the management of COI. COI provisions might not be sufficient to reduce industry influence and that interactions with industry can be ethically problematic and may influence public health policy, research and practice even when COI policies are not implemented. ${ }^{43}{ }^{44}$ We identified four main types of mechanisms to address undue influence from corporations (categories are not mutually exclusive): (i) managing the interactions with industry and COI; (ii) increasing transparency about these interactions and COI; (iii) identifying, monitoring and educating third parties in academia, civil society and the media about the practices of corporations and associated risks to public health; and (iv) prohibiting any interaction with industry. There are other types of mechanisms discussed in the literature, such as the protection of whistle-blowers, or mandatory taxes for companies to be used by an independent organisation to fund public health research and practice, as detailed below.

\section{Governments and international organisations}

International organisations and governments have a mandate to protect and promote public health. Governments are in charge of the initiation, development, implementation and evaluation of public health policies. As such, they are a primary target of corporations whose profits might be threatened by such policies, during all phases of the policy cycle but in particular during initiation and development of policies.

In our scoping review, we identified 23 mechanisms for addressing and/or managing the influence of corporations on governments and international organisations (table 1).

There are growing concerns about how international organisations, including the WHO, engage with corporations and in response, the WHO has recently addressed some of these concerns, most notably in its Framework for Engagement with non-State Actors (FENSA) ${ }^{37} 45$ There is criticism of FENSA, as it could be interpreted as an invitation for increased collaboration between the WHO and industry, suggesting that this is acceptable if managed as per WHO guidelines. ${ }^{46}$

The Organisation for Economic Co-operation and Development (OECD) published several documents that are relevant for the current scoping review, including guidelines for the management of conflicts of interest. ${ }^{478}$ In 2017, it developed a framework for 'Preventing Policy Capture'. ${ }^{49}$ It also published a series of reports on lobbying regulation $^{50}$ and on the funding of political parties and elections campaigns. $^{51}$

The World Bank developed a 'Public Accountability Mechanisms Initiative', which includes specific recommendations and "provides assessments of countries' in-law and in-practice efforts to enhance the transparency of public administration and the accountability of public officials". ${ }^{52}$ 


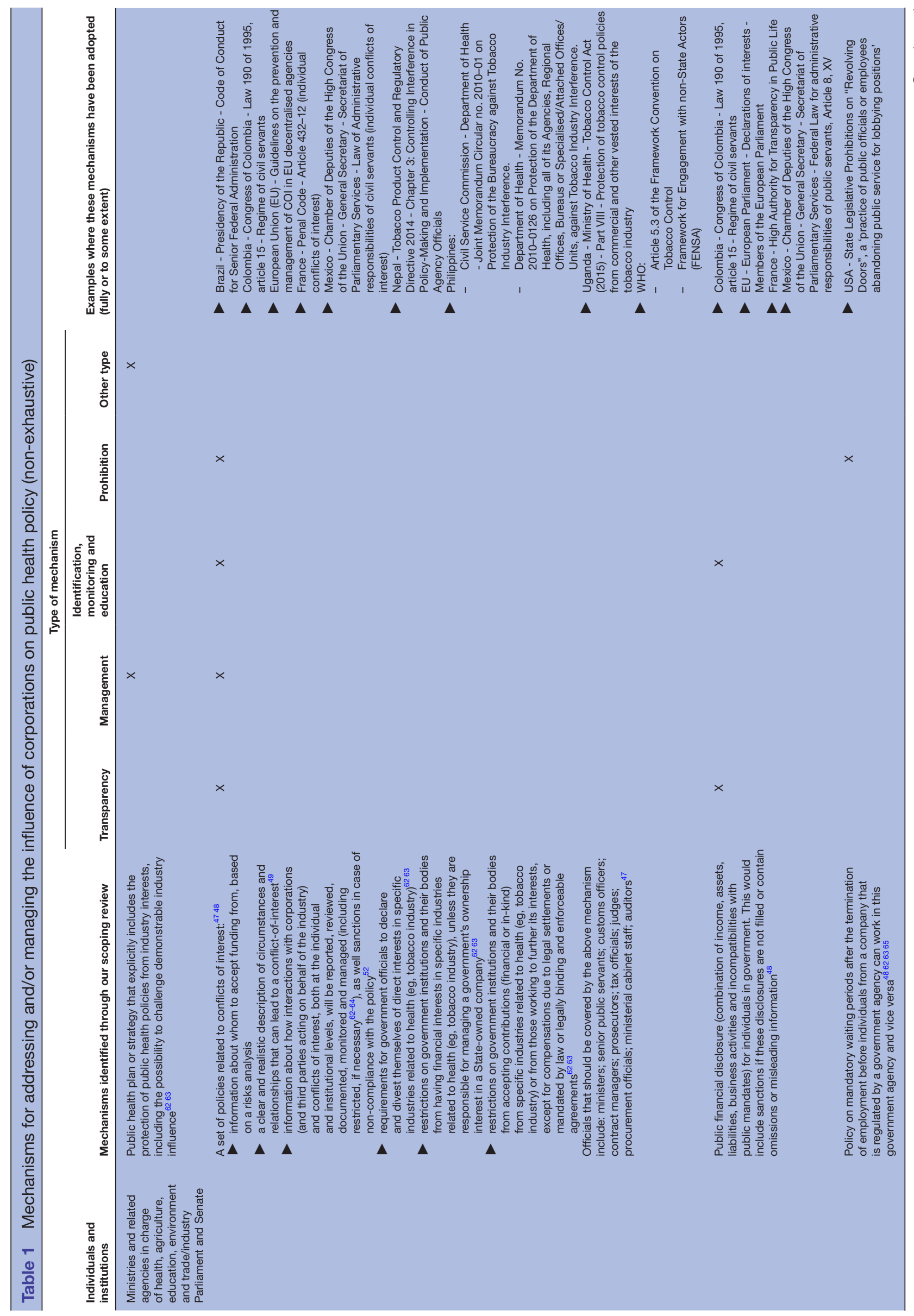

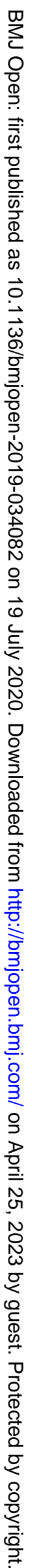




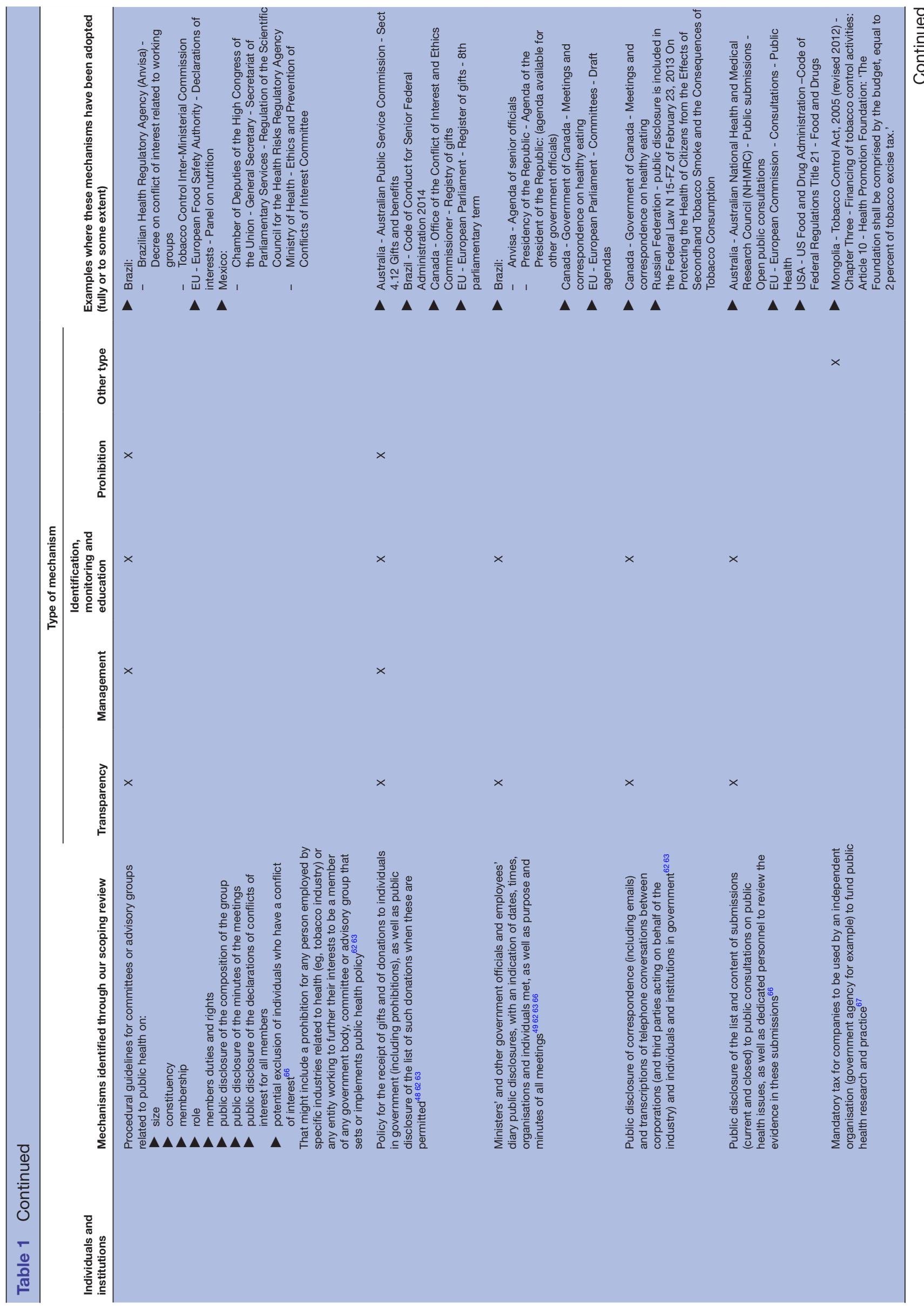

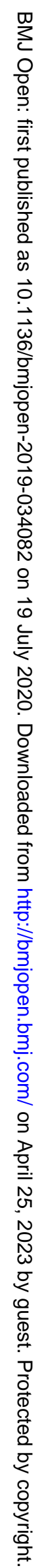




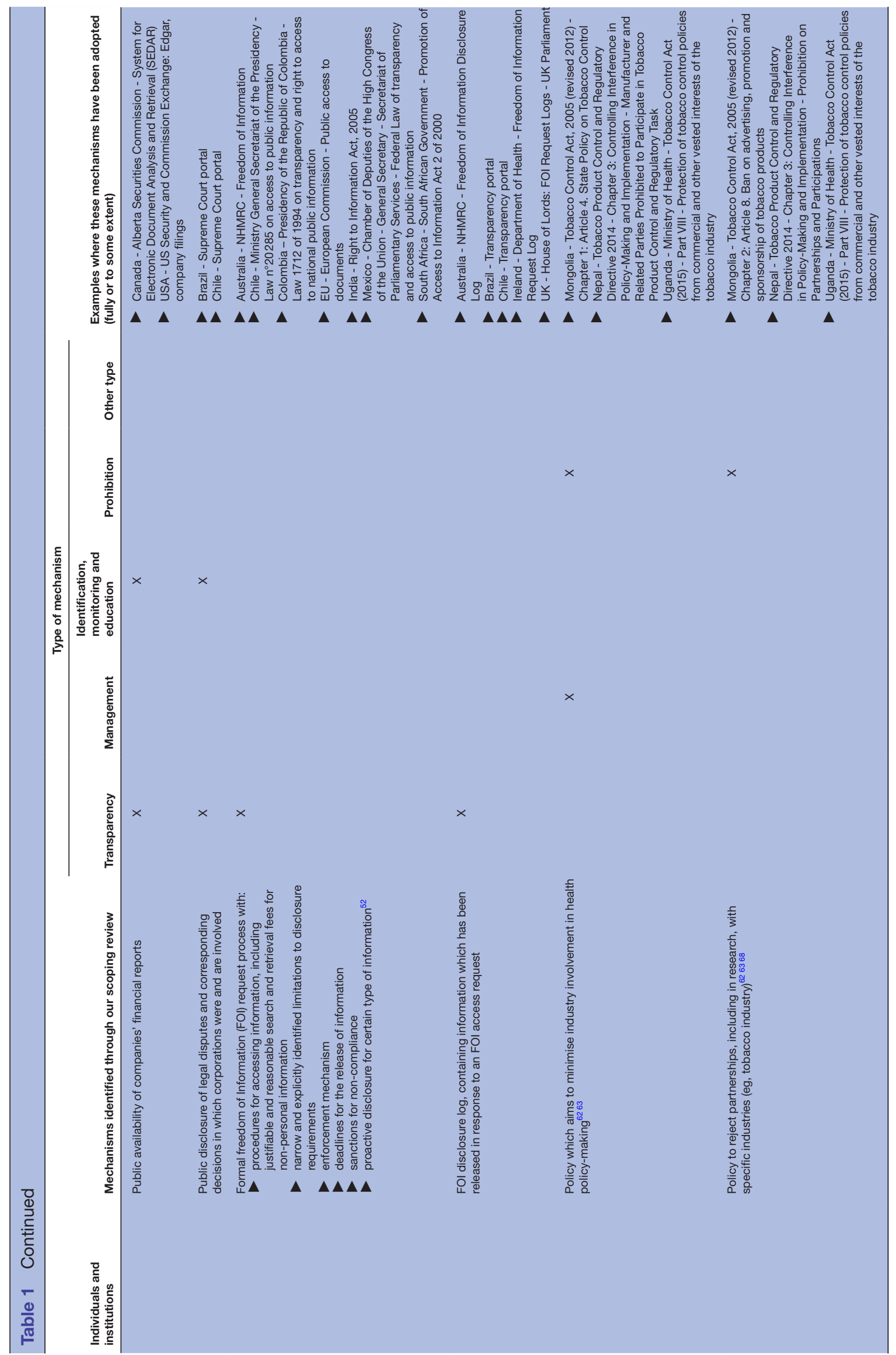

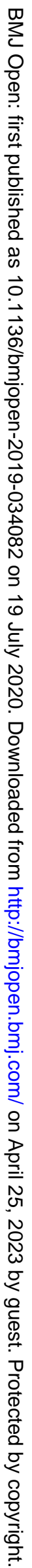




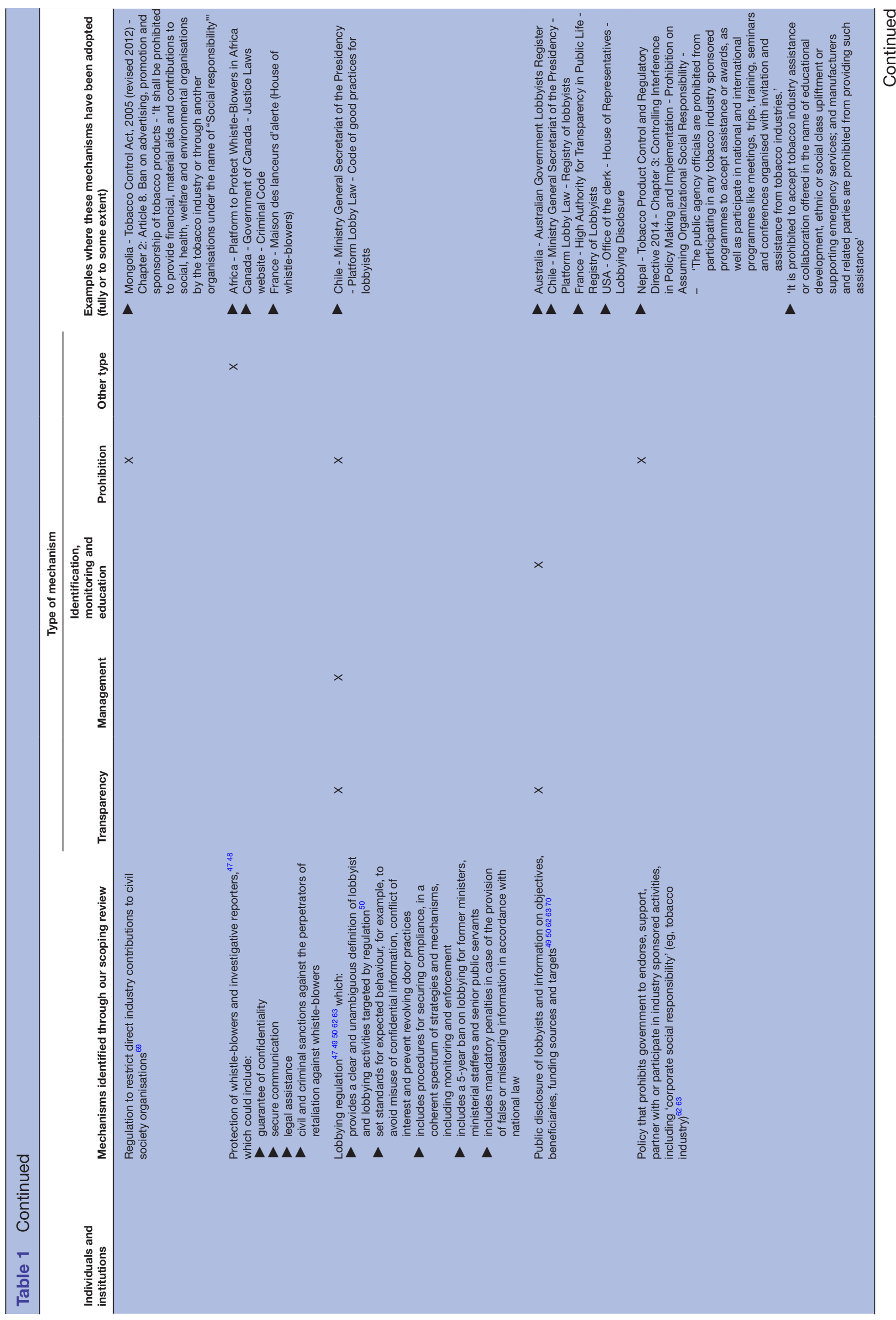

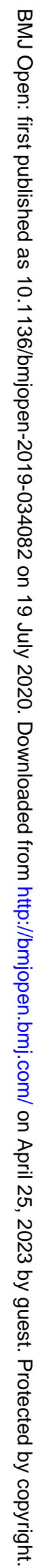




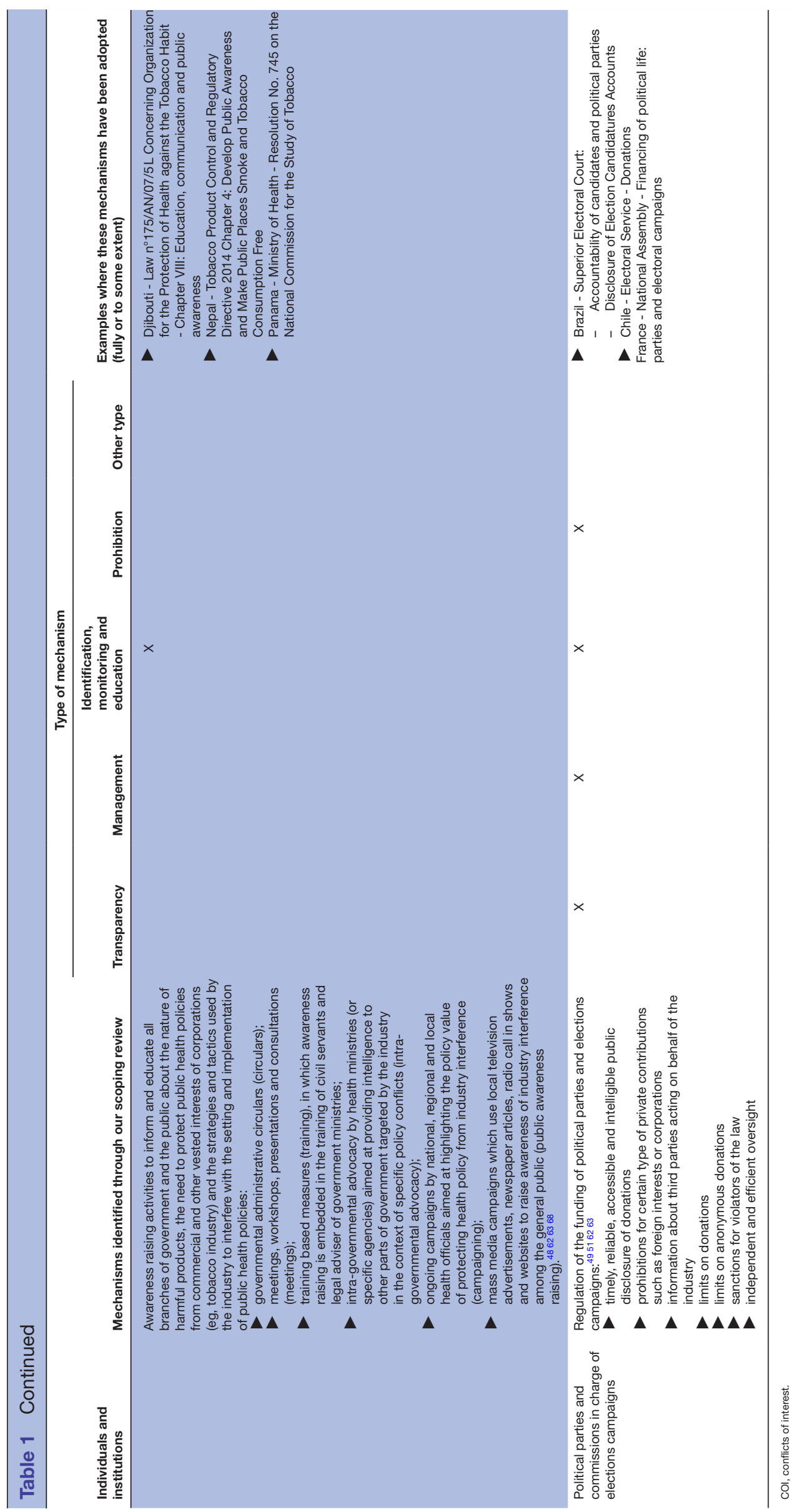

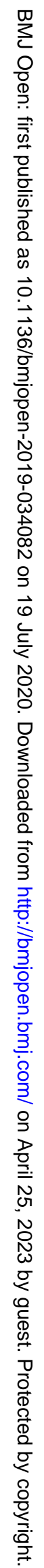


Many countries and international organisations have internal policies and procedures to manage COI, some of which require the disclosure of these interests to the public. There are, in addition, existing tools that can help in assessing risks to individuals and institutions in public health when they are considering engaging with corporations, such as the Purpose, Extent, Relevant-harm, Identifiers, Link (PERIL) indicators ${ }^{53}$ or the decision-making tool developed by the WHO for the prevention and management of COI in nutrition programmes. ${ }^{54}$

For 22 of the 23 mechanisms identified in our scoping review, we found evidence of their adoption, in different parts of the world, to various degrees. Many of the examples identified in table 1 refer to the interactions of governments and international organisations with the tobacco industry, following the ratification of the WHO FCTC. However, no country, to date, has entirely restricted the influence of corporations on public policy.

\section{Academia, the media and the civil society}

We identified, through our systematic searches, 26 mechanisms for addressing and managing the influence of corporations on academia, the media and the civil society (table 2).

Individuals and institutions in academia, the media and the civil society (including public health professionals, civil society organisations, and so on) often engage with corporations, through the sponsorship of events, funding of research project, scientific awards or other types of interactions. These are standard practices, and while there are multiple reasons for them to happen, the scarcity of public funding and the vast resources of corporations are often mentioned. ${ }^{43}$ There is, however, growing concern that the influence of the industry poses threats to the independence, integrity and credibility of these individuals and institutions. ${ }^{295-61}$

We found examples, from across the world, where these 21 of these 26 mechanisms have been adopted. Some universities refuse funding from the tobacco industry; some make transparent interactions between their staff members, students and corporations. Many institutions in academia and civil society have conflicts of interest policies, which is also the case for some scientific journals and professionals associations. The provision of education in universities, conferences and other meetings and to journalists was also cited.

\section{DISCUSSION}

Our searches identified 49 mechanisms for addressing and/or managing the influence of corporations on public health policy, research and practice. The primary purposes of the mechanisms identified are to manage conflicts of interest and increase the transparency of public-private interactions. Based on publicly available information, we found that 43 of these mechanisms had been adopted, although we could not confirm that they had all been implemented and had been determined to be effective.

There is currently limited research in this area, with only a few peer-reviewed scientific articles published in the literature. We also noted that there is a lack of research from low-income or middle-income countries. We identified limited evidence on mechanisms targeted at the media and the civil society, compared with those targeted at governments and academia. We found no information for schools on ways to address and manage the influence of corporations on their institutions, in relation to public health (for example, through the provision of health or nutrition education or physical activity programmes). We identified limited information about mechanisms that could address the influence of corporations; most mechanisms seek to manage that influence (through transparency, for example). Managing the influence of corporations is an important first step, but is not sufficient, or could even be counterproductive in some circumstances. ${ }^{44}$

To our knowledge, this review is the first attempt to develop an inventory of mechanisms to address and manage the influence of corporations on public health policy, research and practice. Among its strengths is its breadth. Although we limited our searches to mechanisms developed to address and/or manage the influence of the alcohol, food, gambling, oil, pharmaceutical and tobacco industries, many of the mechanisms identified in our review were developed with no restriction on the type of industries targeted. Hence this inventory may help in building efforts to address and/or manage the influence of all types of industries.

The list compiled here is non-exhaustive and by nature, subject to changes, as an increasing number of governments and other institutions take measures to prevent undue influence from industry. It rather was intended to be a first attempt to identify mechanisms that exist across the globe, as well as examples where these mechanisms have been adopted. It thus provides a firm footing for further work in this area.

In this scoping review, we did not assess the quality of the included studies, as we only used them to identify mechanisms. In addition, mechanisms at the subnational level were not included here and might be the subject of future investigations. Moreover, we excluded work funded by the industry, but it is possible that some authors did not declare their sources of funding in the publications. In this case, their work is included in our analysis, which represents a COI with regards to the issues at stake.

Ideally, corporations should refrain from influencing public health policy, research and practice. Governments, international organisations, academia, the media and the civil society should avoid interacting with corporations whose interests risk damaging their independence, integrity and credibility. ${ }^{43}$ However, in reality, these interactions often are the default approach in public health, probably driven by a strong influence exerted by businesses. ${ }^{43}$ These interactions, the reasons for them to happen and 


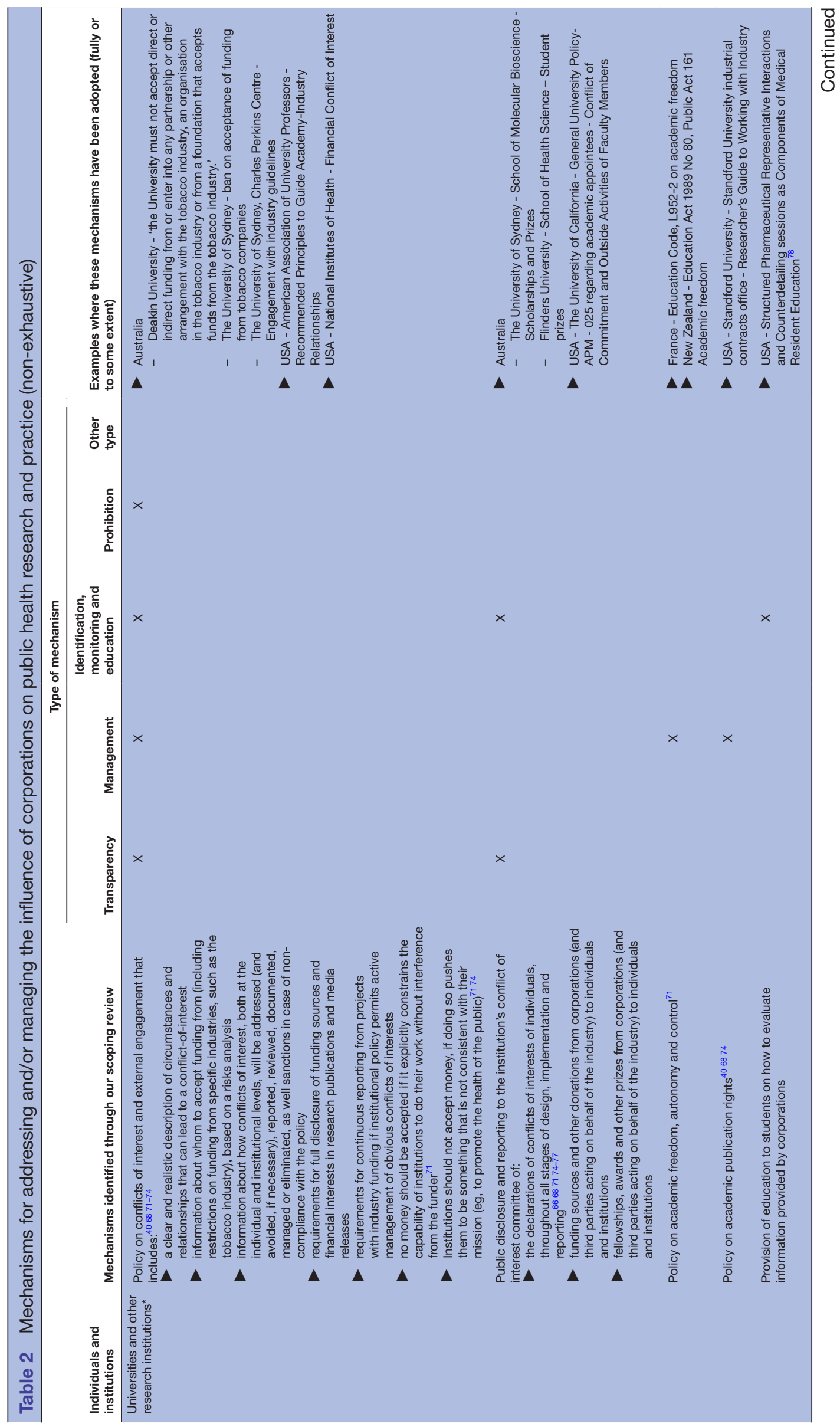

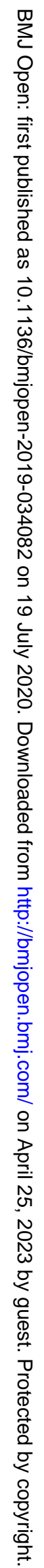




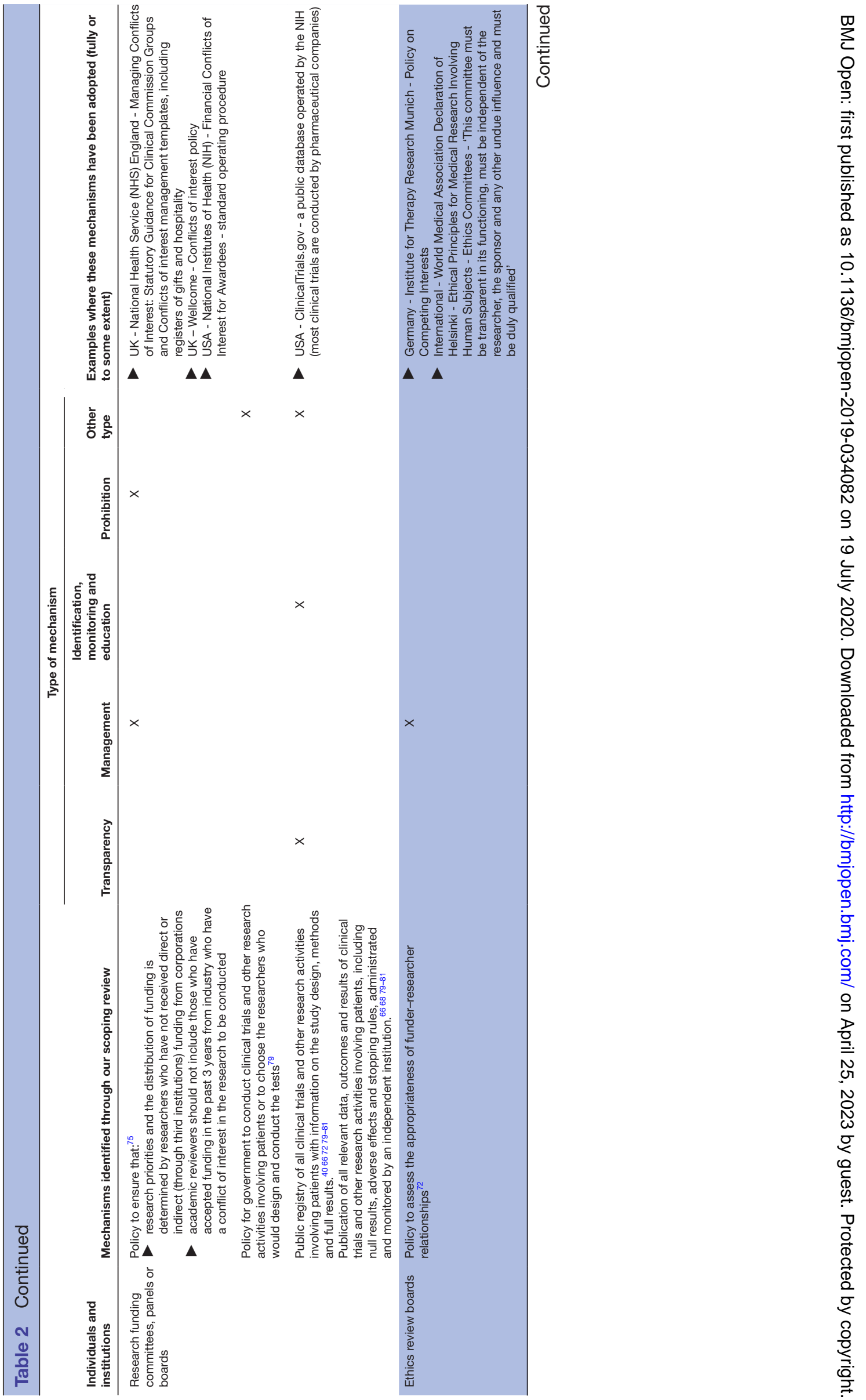




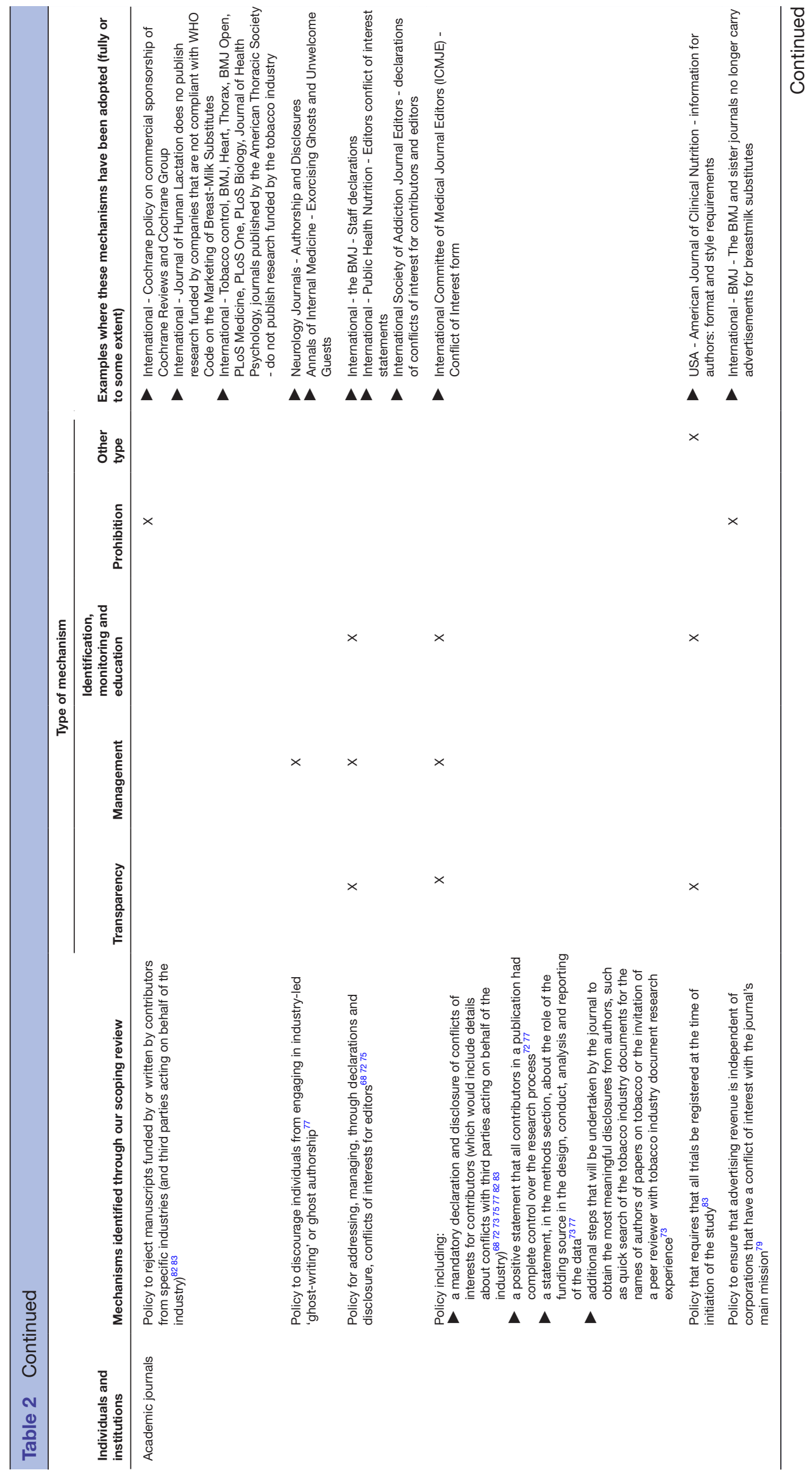

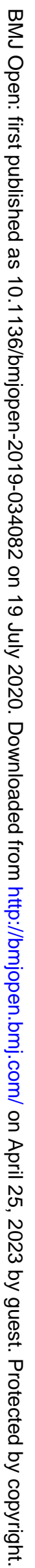




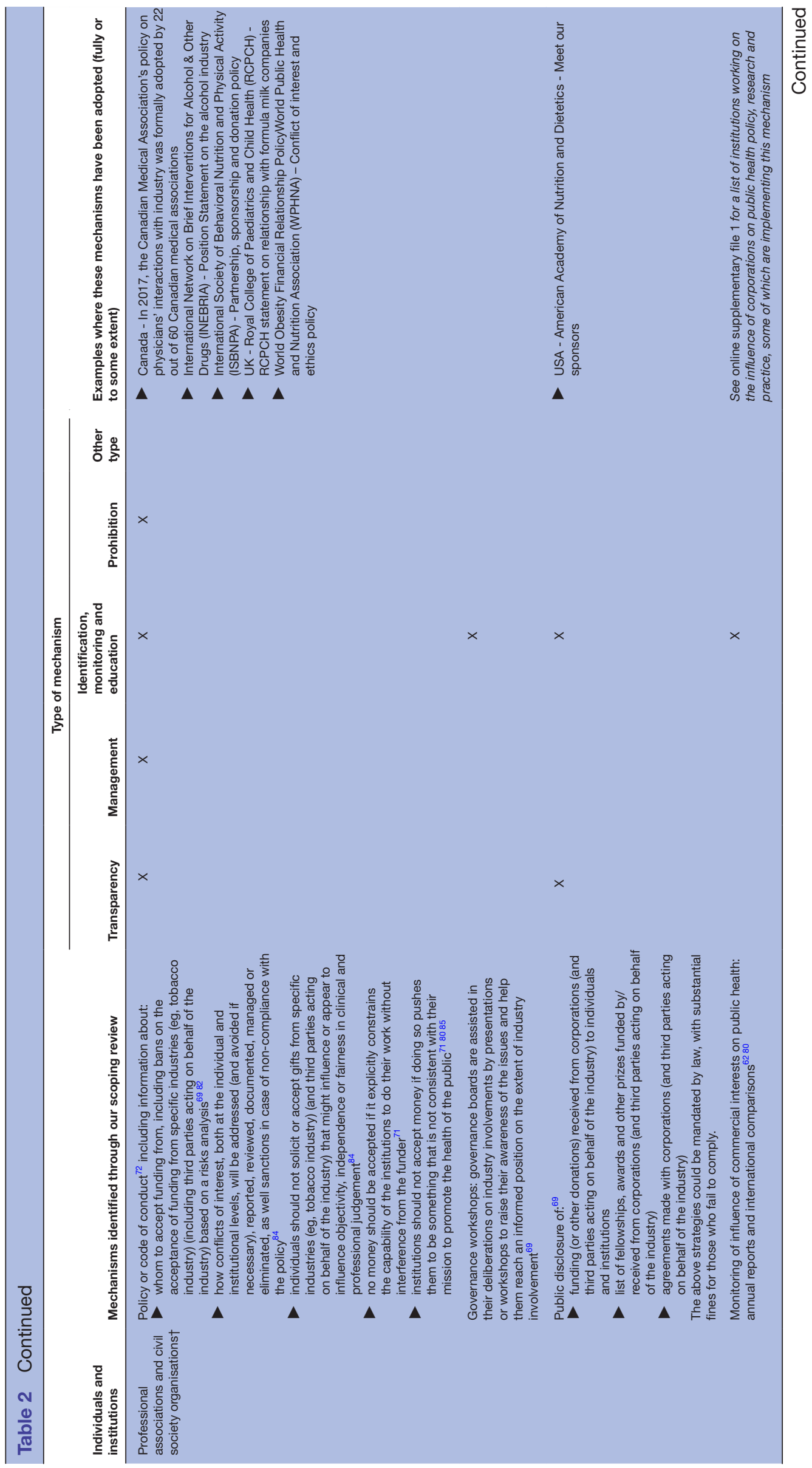

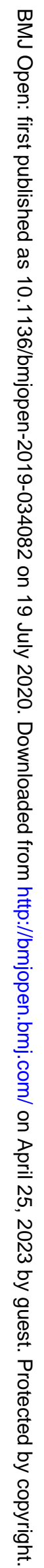




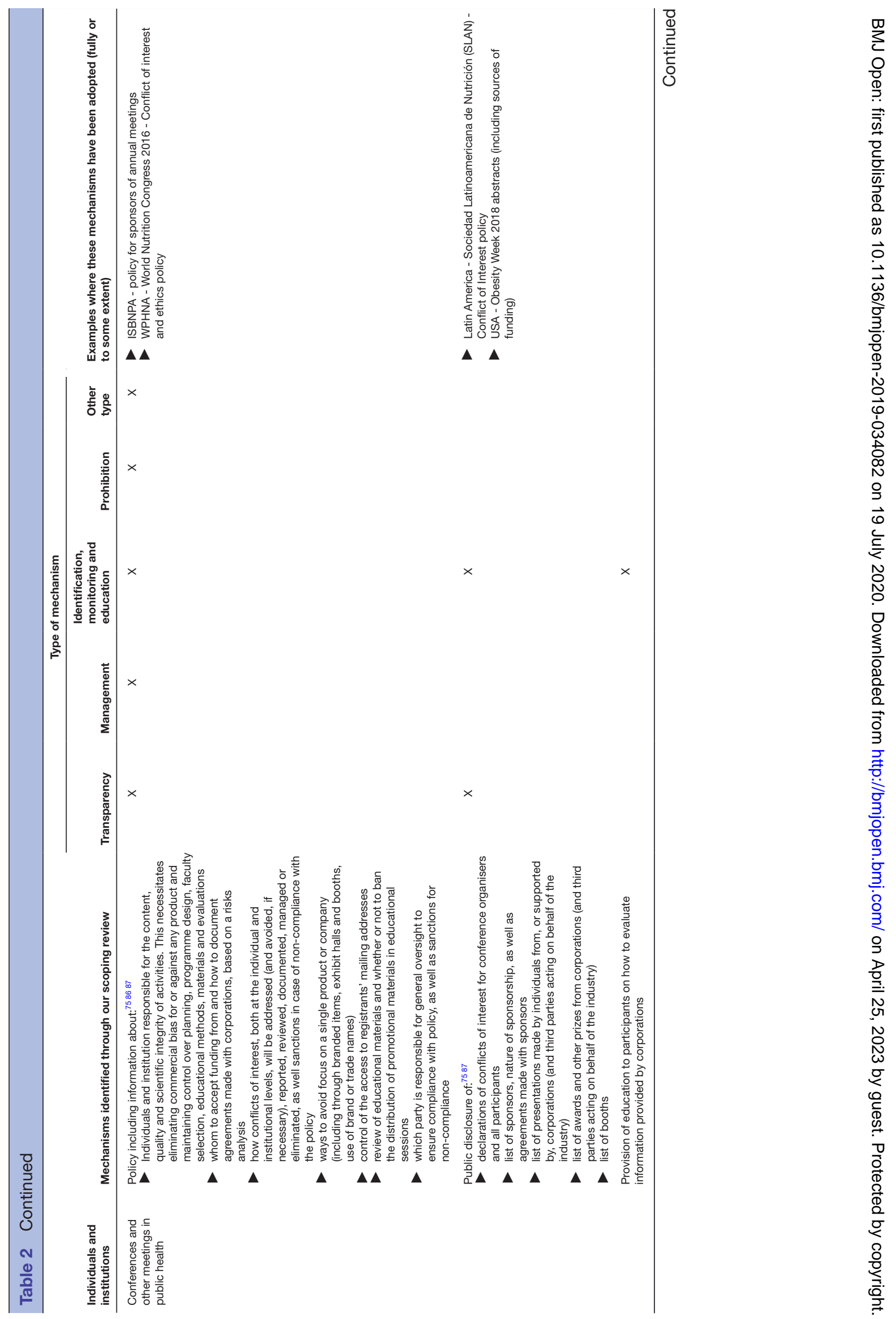




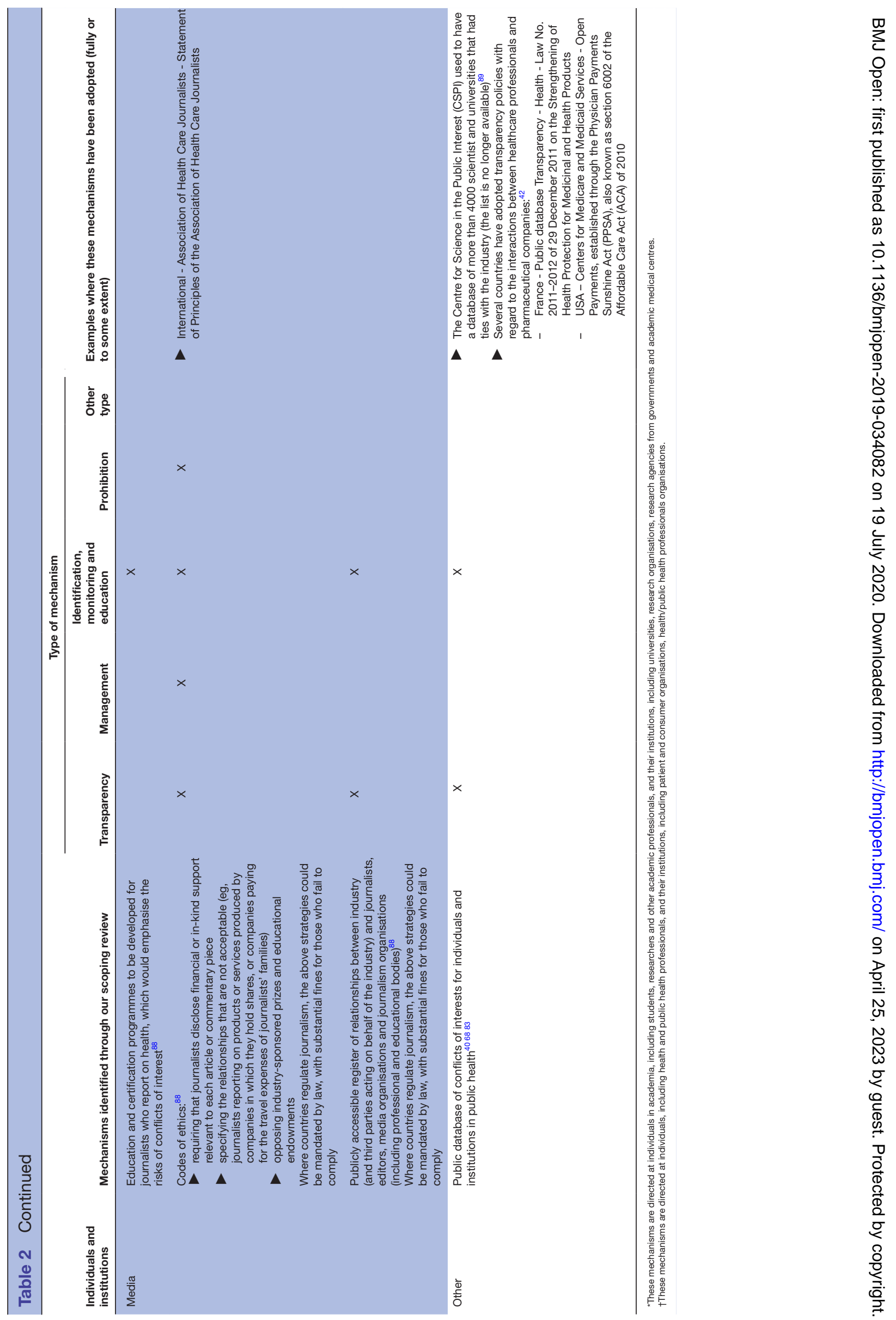


associated risks for public health were recently discussed in the literature. ${ }^{43}$ Public institutions sometimes lack resources, particularly financial resources, to address urgent public health issues. ${ }^{43}$ Academic institutions might want to contribute to the economic development in their country, thus partnering with corporations. ${ }^{43}$ The current situation is perhaps challenging, but there is scope (and need) for change. Many of the examples we identified in our review related to the implementation of the WHO FCTC, the only global treaty that explicitly addresses the interference of an industry with public health policy. The proposed FCFS and FCAC are therefore potential solutions to address and manage the influence that vested interests could have on public health policy, research and practice. If adopted and evaluated more widely, many of the mechanisms described in this manuscript could contribute to efforts to prevent and control noncommunicable diseases.

More research on each of these mechanisms is needed, including on their effectiveness in addressing and/or managing the influence of corporations on public health policy, research and practice. There is a need to understand if these mechanisms are effective in addressing the influence of all industries, or of only some industries, and then study the political, social and other factors responsible for these differences. Collectively, public health professionals might also develop, in the future, new mechanisms not described in our manuscript. Some countries have already adopted some of the mechanisms proposed in this manuscript; others have done little, including countries facing strong resistance to developing and implementing them. An evaluation of the implementation of these mechanisms, which could include a benchmarking exercise, is therefore needed and will inform governments, universities and other actors in public health. In addition to these mechanisms, a module on 'corporations and health' could be part of the curriculum for professionals being trained in public health policy, research or practice. Conferences and other meetings of public health professionals should also be used as a platform where to discuss the influence of the industry on public health policy, research and practice. This may be particularly important in the case of academic conferences which involve extensive resources and input from and partnerships with corporations, such as nutrition and gambling conferences.

In conclusion, corporations have significant economic and political power, which may, in some circumstances, be detrimental to public health. We identified several mechanisms that could help address and/or manage that influence. The development, implementation and monitoring of these mechanisms seem crucial to protect public health from the commercial interests of industry actors.

\section{Author affiliations}

${ }^{1}$ School of Public Health, University of Sao Paulo, Sao Paulo, Brazil

${ }^{2}$ School of Nutrition and Dietetics, University of Antioquia, Medellin, Colombia

${ }^{3}$ Sciensano, Brussels, Brussels, Belgium
${ }^{4}$ World Public Health Nutrition Association, London, UK

${ }^{5}$ Charles Perkins Centre and School of Pharmacy, Faculty of Medicine and Health, The University of Sydney, Sydney, New South Wales, Australia

${ }^{6}$ Pan American Health Organization, Washington, District of Columbia, USA

${ }^{7}$ Faculty of Public Health and Policy, London School of Hygiene and Tropical Medicine, London, UK

${ }^{8}$ Dondena Research Centre and Department of Policy Analysis and Public

Management, Bocconi University, Milano, Lombardia, Italy

${ }^{9} \mathrm{Global}$ Obesity Centre, Deakin University, Burwood, Victoria, Australia

\section{Twitter Martin McKee @martinmckee}

Acknowledgements The authors would like to acknowledge Jaramillo Ferney, a librarian at the University of Antioquia, for his support during the development of the search strategy for this scoping review.

Contributors MM and GS contributed to the conception of the work, with support from SV and LB. MM led data collection and analysis, with support from SV, AC-L, $L B, F G, M P, M M c K$ and GS. MM led the writing of the manuscript and all authors have substantively revised it. All authors have approved the submitted version. All authors have agreed both to be personally accountable for the author's own contributions and to ensure that questions related to the accuracy or integrity of any part of the work, even ones in which the author was not personally involved, are appropriately investigated, resolved and the resolution documented in the literature.

Funding MM received a Fellowship from the São Paulo Research Foundation (FAPESP), Brazil (grant number 2017/24744-0). MM obtained seed funding from the Faculty of Health Sciences (FHS) at the American University of Beirut (AUB), as part of a grant funded by the International Development Research Centre (IDRC). This funding supported her fieldwork in Colombia and Chile in 2019. DS is funded by a Wellcome award.

\section{Competing interests None declared.}

Patient consent for publication Not required.

Provenance and peer review Not commissioned; externally peer reviewed.

Data availability statement Data are available upon reasonable request. The data sets used and/or analysed during the current study are available from the corresponding author on reasonable request.

Open access This is an open access article distributed in accordance with the Creative Commons Attribution Non Commercial (CC BY-NC 4.0) license, which permits others to distribute, remix, adapt, build upon this work non-commercially, and license their derivative works on different terms, provided the original work is properly cited, appropriate credit is given, any changes made indicated, and the use is non-commercial. See: http://creativecommons.org/licenses/by-nc/4.0/.

\section{ORCID iDs}

Melissa Mialon http://orcid.org/0000-0002-9883-6441

Martin McKee http://orcid.org/0000-0002-0121-9683

\section{REFERENCES}

1 Moodie R, Stuckler D, Monteiro C, et al. Profits and pandemics: prevention of harmful effects of tobacco, alcohol, and ultraprocessed food and drink industries. Lancet 2013;381:670-9.

2 World Health Organization. Opening address - Dr Margaret Chan Director-General of the World Health Organization. 8th global conference on health promotion Helsinki, Finland, 2013.

3 Swinburn BA, Kraak VI, Allender S, et al. The global syndemic of obesity, undernutrition, and climate change: the lancet commission report. Lancet 2019;393:791-846.

4 State of California - Department of Justice - Office of the Attorney General. Master settlment agreement, 2017. Available: http://oag.ca. gov/tobacco/msa

5 University of California San Francisco. Truth tobacco industry documents, 2017. Available: https://www.industrydocumentslibrary. ucsf.edu/tobacco/

6 Gilmore AB, Fooks G, Drope J, et al. Exposing and addressing tobacco industry conduct in low-income and middle-income countries. Lancet 2015;385:1029-43.

7 Savell E, Gilmore AB, Fooks G. How does the tobacco industry attempt to influence marketing regulations? A systematic review. PLoS One 2014;9:e87389.

8 Ulucanlar S, Fooks GJ, Gilmore AB. The policy dystopia model: an interpretive analysis of tobacco industry political activity. PLoS Med 2016;13:e1002125. 
9 Costa H, Gilmore AB, Peeters S, et al. Quantifying the influence of the tobacco industry on EU governance: automated content analysis of the EU tobacco products Directive. Tob Control 2014;23:473-8.

10 Peto R, Lopez AD, Boreham J, et al. Mortality from smoking in developed countries 1950-2000. 2 edn, 2006.

11 Mialon M, Swinburn B, Sacks G. A proposed approach to systematically identify and monitor the corporate political activity of the food industry with respect to public health using publicly available information. Obes Rev 2015;16:519-30.

12 McCambridge J, Mialon M, Hawkins B. Alcohol industry involvement in policymaking: a systematic review. Addiction 201810.1111/ add.14216. [Epub ahead of print: 15 Mar 2018].

13 Savell E, Fooks G, Gilmore AB. How does the alcohol industry attempt to influence marketing regulations? A systematic review. Addiction 2016;111:18-32.

14 Oreskes N, Conway E. Merchants of doubt: how a handful of scientists obscured the truth on issues from tobacco smoke to global warming, 2011

15 Hancock L, Ralph N, Martino FP. Applying corporate political activity (CPA) analysis to Australian gambling industry submissions against regulation of television sports betting advertising. PLoS One 2018;13:e0205654.

16 Kickbusch I, Allen L, Franz C. The commercial determinants of health. Lancet Glob Health 2016;4:e895-6.

17 Madureira Lima J, Galea S. The corporate permeation index - a tool to study the macrosocial determinants of non-communicable disease. SSM Popul Health 2019;7:100361.

18 World Health Organization. Technical resource on the protection of public health policies with respect to tobacco control from commercial and other vested interests of the tobacco industry for country implementation of who framework convention on tobacco control article 5.3. Geneva, 2012.

19 Southeast Asia Tobacco Control Alliance (SEATCA). Surveillance of tobacco industry activities toolkit. Thailand, 2009.

20 Tobacco Control Research Group. Tobaccotactics, 2013. Available: http://www.tobaccotactics.org/index.php/Main Page

21 Mialon M, Swinburn B, Allender S, et al. Systematic examination of publicly-available information reveals the diverse and extensive corporate political activity of the food industry in Australia. BMC Public Health 2016;16:283.

22 Mialon M, Swinburn B, Wate J, et al. Analysis of the corporate political activity of major food industry actors in Fiji. Global Health 2016;12:18.

23 Mialon M, Mialon J. Analysis of corporate political activity strategies of the food industry: evidence from France. Public Health Nutr 2018;21:3407-21.

24 Mialon M, Mialon J. Corporate political activity of the dairy industry in France: an analysis of publicly available information. Public Health Nutr 2017;20:2432-9.

25 Mialon M, Gomes FdaS. Public health and the ultra-processed food and drink products industry: corporate political activity of major transnationals in Latin America and the Caribbean. Public Health Nutr 2019;22:1898-908.

26 Jaichuen N, Phulkerd S, Certthkrikul N, et al. Corporate political activity of major food companies in Thailand: an assessment and policy recommendations. Global Health 2018;14:115.

27 Tselengidis A, Östergren P-O. Lobbying against sugar taxation in the European Union: analysing the lobbying arguments and tactics of stakeholders in the food and drink industries. Scand J Public Health 2019;47:565-75.

28 Friends of the UN HLM on NCDs. The how: a message for the un high-level meeting on NCDS. Lancet 2018;392:e4-5.

29 Moynihan R, Macdonald H, Heneghan C, et al. Commercial interests, transparency, and independence: a call for submissions. BMJ 2019;365:11706.

30 Baum FE, Margaret Anaf J. Transnational corporations and health: a research agenda. Int J Health Serv 2015;45:353-62.

31 Baum FE, Sanders DM, Fisher M, et al. Assessing the health impact of transnational corporations: its importance and a framework. Global Health 2016;12:27.

32 World Health Organization. WHO framework convention on tobacco control. Geneva, 2003.

33 The Lancet . A framework convention on alcohol control. Lancet 2007;370:1102

34 World Health Organization.. Parties to the WHO framework convention on tobacco control. Available: https://www.who.int/fctc/ cop/en/ [Accessed 6 Feb 2019].

35 Gravely S, Giovino GA, Craig L, et al. Implementation of key demand-reduction measures of the who framework convention on tobacco control and change in smoking prevalence in 126 countries: an association study. Lancet Public Health 2017;2:e166-74.
36 McCambridge J, Daube M, McKee M. Brussels declaration: a vehicle for the advancement of tobacco and alcohol industry interests at the science/policy interface? Tob Control 2019;28:7-12.

37 World Health Organization. Sixty-fifth World health assembly WHA65.6 agenda item 13.3. Geneva: World Health Organization, 2012.

38 Torjesen I. Exclusive: partnering with alcohol industry on public health is not okay, who says. BMJ 2019;365:11666.

39 McCambridge J, Mialon M. Alcohol industry involvement in science: a systematic review of the perspectives of the alcohol research community. Drug Alcohol Rev 2018;37:565-79.

40 Cullerton K, Adams J, Forouhi N, et al. What principles should guide interactions between population health researchers and the food industry? systematic scoping review of peer-reviewed and grey literature. Obes Rev 2019;20:1073-84.

41 Cochrane Training. Scoping reviews: what they are and how you can do them. Available: https://training.cochrane.org/resource/scopingreviews-what-they-are-and-how-you-can-do-them [Accessed 9 Aug 2019].

42 Fabbri A, Santos Ala, Mezinska S, et al. Sunshine policies and murky shadows in Europe: disclosure of pharmaceutical industry payments to health professionals in nine European countries. Int $\mathrm{J}$ Health Policy Manag 2018;7:504-9.

43 Marks JH. The' ' perils of partnership: Industry influence, institutional integrity, and public health. New York: Oxford University Press.

44 Goldberg DS. The shadows of sunlight: why disclosure should not be a priority in addressing conflicts of interest. Public Health Ethics 2018.

45 World Health Organization. About WHO: WHO's engagement with non-state actors, 2016. Available: http://www.who.int/about/ collaborations/non-state-actors/en/

46 Khayatzadeh-Mahani A, Ruckert A, Labonté R. Could the WHO's framework on engagement with Non-State actors (FENSA) be a threat to tackling childhood obesity? Glob Public Health 2018;13:1337-40.

47 Bank AD. Organisation for economic co-operation and development managing conflict of interest: frameworks, tools, and instruments for preventing, detecting, and managing conflict of interest. Mandaluyong City, Metro Manila, Philippines: Asian Development Bank, 2008.

48 Organization For Economic Co-operation and Development. Managing conflict of interest in the public sector: a toolkit, 2005.

49 Organization For Economic Co-operation and Development. Preventing policy capture: integrity in public decision making. Available: https://doi.org/10.1787/9789264065239-en [Accessed 9 Apr 2019].

50 Organization For Economic Co-operation and Development. Transparency and integrity in lobbying, 2013.

51 Organization For Economic Co-operation and Development. Financing democracy: funding of political parties and election campaigns and the risk of policy capture, 2016.

52 Bank W. Public sector governance - public accountability, echanisms, 2013. Available: http://web.worldbank.org/WBSITE/ EXTERNAL/TOPICS/EXTPUBLICSECTORANDGOVERNANCE/0,, contentMDK:23352107 pagePK:148956 piPK:216618 theSitePK: 286305,00.html [Accessed 5 Feb 2019]

53 Adams PJ. Assessing whether to receive funding support from tobacco, alcohol, gambling and other dangerous consumption industries. Addiction 2007;102:1027-33.

54 World Health Organization. Draft approach for the prevention and management of conflicts of interest in the policy development and implementation of nutrition programmes at country level: decisionmaking process and tool, 2017.

55 Hennessy M, Cullerton K, Baker P, et al. Time for complete transparency about conflicts of interest in public health nutrition research. HRB Open Res 2019;2:1.

56 Mart S, Giesbrecht N. Red flags on pinkwashed drinks: contradictions and dangers in marketing alcohol to prevent cancer. Addiction 2015;110:1541-8.

57 Freedhoff $Y$, Hébert PC. Partnerships between health organizations and the food industry risk derailing public health nutrition. CMAJ 2011;183:291-2.

58 Jacobson MF. Lifting the veil of secrecy from industry funding of nonprofit health organizations. Int J Occup Environ Health 2005;11:349-55.

59 Arie S. Nestle and PepsiCo will give nutritional advice to women in anti-hunger campaign in Mexico. BMJ 2013;346:f2458.

60 Simon M. Clowning around with charity: how McDonald's exploits philanthropy and targets children. USA: Eat Drink Politics, 2013.

61 Brooks EC. Does truthful advertising ever pass "the smell test" in a peer-reviewed journal? J Hum Lact 2019;35:649-53. 
62 Fooks GJ, Smith J, Lee K, et al. Controlling corporate influence in health policy making? an assessment of the implementation of article 5.3 of the world Health organization framework convention on tobacco control. Global Health 2017:13:12.

63 World Health Organization. Guidelines for implementation of Article 5.3 of theWHO Framework Convention on Tobacco Control' ' on the protection of public health policies with respect to tobacco control from commercial and other vested interests of the tobacco industry, 2008.

64 Swinburn B, Vandevijvere S, Kraak V, et al. Monitoring and benchmarking government policies and actions to improve the healthiness of food environments: a proposed government healthy food environment policy index. Obes Rev 2013;14 Suppl 1:24-37.

65 Balwicki Łukasz, Stokłosa M, Balwicka-Szczyrba M, et al. Tobacco industry interference with tobacco control policies in Poland: legal aspects and industry practices. Tob Control 2016;25:521-6.

66 Dhalla I, Laupacis A. Moving from opacity to transparency in pharmaceutical policy. CMAJ 2008;178:428-31.

67 Nestle M. Unsavory truth: how food companies skew the science of what we eat. 1 edn. New York: Basic Books, 2018

68 Stenius K, Babor TF. The alcohol industry and public interest science. Addiction 2010;105:191-8.

69 Adams PJ, Rossen F. Reducing the moral jeopardy associated with receiving funds from the proceeds of gambling. $J$ Gambl Issues 2006;11.

70 Reeve B, Gostin LO. "Big" food, tobacco, and alcohol: reducing industry influence on noncommunicable disease prevention laws and policies comment on "addressing ncds: challenges from industry market promotion and interferences". Int J Health Policy Manag 2019;8:450-4.

71 Galea S, Saitz R, Funding SR. Funding, institutional conflicts of interest, and schools of public health: realities and solutions. JAMA 2017;317:1735-6.

72 Miller P, Babor TF, McGovern T, et al. Relationships with the Alcoholic-Beverage Industry, Pharmaceutical Companies, and Other Funding Agencies: Holy Grail or Poisoned Chalice? In: Babor TF, Stenius K, Pates R, et al, eds. Publishing addiction science: a guide for the Perplexe. London: Ubiquity Press, 2017: 323-52.

73 Bero LA, Glantz S, Hong M-K. The limits of competing interest disclosures. Tob Control 2005;14:118-26.

74 Mozaffarian D. Conflict of interest and the role of the food industry in nutrition research. JAMA 2017;317:1755-6.
75 Livingstone C, Adams PJ. Clear principles are needed for integrity in gambling research. Addiction 2016;111:5-10.

$76 \mathrm{Gmel}$ G. The good, the bad and the ugly. Addiction 2010;105:203-5.

77 Laine C, Mulrow CD. Exorcising ghosts and unwelcome guests. Ann Intern Med 2005;143:611.

78 Wall GC, Smith HL, Craig SR, et al. Structured pharmaceutical representative interactions and counterdetailing sessions as components of medical resident education. J Pharm Pract 2013;26:151-6.

79 Rodwin MA. Conflicts of interest, institutional corruption, and pharma: an agenda for reform. J Law Med Ethics 2012;40:511-22.

80 Spelsberg A, Martiny A, Schoenhoefer PS, et al. Is disclosure of potential conflicts of interest in medicine and public health sufficient to increase transparency and decrease corruption? J Epidemiol Community Health 2009;63:603-5.

81 Poli A, Marangoni F, Agostoni CV, et al. Research interactions between academia and food companies: how to improve transparency and credibility of an inevitable liaison. Eur J Nutr 2018;57:1269-73.

82 Babor TF. How should we define, document, and prevent conflicts of interest in alcohol research? Int J Alcohol Drug Res 2016;5:5.

83 Lesser LI. Reducing potential bias in industry-funded nutrition research. Am J Clin Nutr 2009;90:699-700.

84 American College of Clinical Pharmacy, Hatton RC, Chavez ML, et al. Pharmacists and industry: guidelines for ethical interactions. Pharmacotherapy 2008;28:410-20.

85 Portugal C, Cruz TB, Espinoza L, et al. Countering tobacco industry sponsorship of Hispanic/Latino organizations through policy adoption: a case study. Health Promot Pract 2004;5:143S-56.

86 Studdert DM, Mello MM, Brennan TA. Financial conflicts of interest in physicians' relationships with the pharmaceutical industry-self-regulation in the shadow of federal prosecution. N Engl J Med 2004;351:1891-900.

87 Shnier A, Lexchin J. Continuing medical education and pharmaceutical industry involvement: an evaluation of policies adopted by Canadian professional medical associations. Int J Risk Saf Med 2017:29:1-16.

88 Lipworth W, Kerridge I, Sweet M, et al. Widening the debate about conflict of interest: addressing relationships between journalists and the pharmaceutical industry. J Med Ethics 2012;38:492-5.

89 Ramsay S. Online database reveals researchers' industry ties. Lancet 2001;357:1677. 